Int. J. Electrochem. Sci., 12 (2017) $4867-4897$

\title{
Theoretical and Experimental Studies of Adsorption Characteristics of Newly Synthesized Schiff Bases and their Evaluation as Corrosion Inhibitors for Mild Steel in 1 M HCl
}

\author{
Amel Ghames ${ }^{1,}$, Tahar Douadi ${ }^{1}$, Saifi Issaadi ${ }^{1}$, Lakhdar Sibous ${ }^{1}$, Khadija Ismaily Alaoui ${ }^{2}$, Mustapha \\ Taleb $^{2}$ and Salah Chafaa ${ }^{1}$ \\ ${ }^{1}$ Laboratoire d'Electrochimie des Matériaux Moléculaires et Complexes, Département de Génie des \\ Procèdes, Faculté de Technologie, Université FERHAT ABBAS - Sétif-1, 19000, Algérie. \\ ${ }^{2}$ Laboratoire d'Ingénierie, d'Electrochimie, de Modélisation et d'Environnement (LIEME), Faculté \\ des Sciences Dhar El Mahraz, Université Sidi Mohamed Ben Abdallah Fès, Maroc. \\ "E-mail: ghamesamel@yahoo.fr
}

doi: $10.20964 / 2017.06 .92$

Received: 13 December 2016 / Accepted: 20 April 2017 / Published: 12 May 2017

A new class of Schiff base compounds viz., 4,4'-bis(2,4-dihydroxybenzaldeyde) diphenylethanediimine (L1) and 4,4'-bis(4-diethlylaminosalicylaldehyde) diphenylethanediimine (L2) have been synthesized and characterized by spectral techniques using Elemental analysis, FTIR, ${ }^{1} \mathrm{H}-$ NMR and mass spectrometry. The inhibition action on corrosion of the Schiff bases on mild steel in 1 $\mathrm{M}$ hydrochloric acid has been studied by the weight loss, potentiodynamic polarization and electrochemical impedance spectroscopy (EIS) methods were applied to study the corrosion at different concentrations of inhibitors. The inhibition efficiency has been compared with their parent amine from which the Schiff bases have been derived. The obtained results showed that L1 and L2 exhibited good inhibition on mild steel in $\mathrm{HCl}$ solution and the inhibition efficiency increased with increasing concentration, reaching a maximum inhibition efficiency of $95.33 \%$ and $94.18 \%$ designated respectively to $\mathrm{L} 1$ and $\mathrm{L} 2$ at $5 \times 10^{-4} \mathrm{M}$ and decreased with increasing the temperature. Polarization study clearly suggested that these Schiff's bases act as mixed-type inhibitors with some cathodic predominance. The adsorption of L1 and L2 obeys Langmuir isotherm. SEM analyses revealed that inhibition occurs due to adsorption of molecules at metal/solution interface. Quantum chemical parameters were calculated using DFT method such as energy gaps support the good inhibiting performance of the two Schiff bases.

Keywords: Corrosion Inhibitors; Weight Loss; Electrochemical Measurements; Density Functional Theory; Fukui indices.

\section{$\underline{\text { FULL TEXT }}$}


(C) 2017 The Authors. Published by ESG (www.electrochemsci.org). This article is an open access article distributed under the terms and conditions of the Creative Commons Attribution license (http://creativecommons.org/licenses/by/4.0/). 